\title{
Front Matter: Volume 8551
}

, "Front Matter: Volume 8551," Proc. SPIE 8551, High-Power Lasers and Applications VI, 855101 (29 November 2012); doi: 10.1117/12.2017923

SPIE. Event: Photonics Asia, 2012, Beijing, China 


\title{
High-Power Lasers and Applications VI
}

\author{
Upendra N. Singh \\ Dianyuan Fan \\ Jianquan Yao \\ Robert F. Walter \\ Editors
}

\section{5-7 November 2012 Beijing, China}

\author{
Sponsored by \\ SPIE \\ COS-Chinese Optical Society
}

\section{Cooperating Organizations}

Tsinghua University (China) • Peking University (China) • Zhejiang University (China) • Beijing Institute of Technology (China) • Beijing University of Posts and Telecommunications (China) • University of Science and Technology of China (China) • Tianjin University (China) • Nankai University (China) • Changchun University of Science and Technology (China) • University of Shanghai for Science and Technology (China) • Capital Normal University (China) • Huazhong University of Science and Technology • Beijing Jiaotong University (China) - Shanghai Institute of Optics and Fine Mechanics (China) • Changchun Institute of Optics and Fine Mechanics (China) - Institute of Semiconductors (China) - Institute of Optics and Electronics (China) Institute of Physics (China) • Shanghai Institute of Technical Physics (China) • China Instrument and Control Society (China) • Optoelectronics Technology Committee, COS (China) • SPIE National Committee in China (China) - Japan Optical Society (Japan) - Korea Optical Society (Korea, Republic of) • Australia Optical Society (Australia) • Singapore Optical Society (Singapore)

Supporting Organizations

CAST_China Association for Science and Technology (China)

NSFC—National Nature Science Foundation (China)

Published by

SPIE

Volume 8551

Proceedings of SPIE 0277-786X, V.8551

SPIE is an international society advancing an interdisciplinary approach to the science and application of light.

High-Power Lasers and Applications VI, edited by Upendra N. Singh, Dianyuan Fan,

Jianquan Yao, Robert F. Walter, Proc. of SPIE Vol. 8551, 855101 · C 2012 SPIE

CCC code: $0277-786 / 12 / \$ 18 \cdot$ doi: $10.1117 / 12.2017923$ 
The papers included in this volume were part of the technical conference cited on the cover and title page. Papers were selected and subject to review by the editors and conference program committee. Some conference presentations may not be available for publication. The papers published in these proceedings reflect the work and thoughts of the authors and are published herein as submitted. The publisher is not responsible for the validity of the information or for any outcomes resulting from reliance thereon.

Please use the following format to cite material from this book:

Author(s), "Title of Paper," in High-Power Lasers and Applications VI, edited by Upendra N. Singh, Dianyuan Fan, Jianquan Yao, Robert F. Walter, Proceedings of SPIE Vol. 8551 (SPIE, Bellingham, WA, 2012) Article CID Number.

ISSN: 0277-786X

ISBN: 9780819493064

Published by

SPIE

P.O. Box 10, Bellingham, Washington 98227-0010 USA

Telephone +1 3606763290 (Pacific Time) · Fax +1 3606471445

SPIE.org

Copyright (@ 2012, Society of Photo-Optical Instrumentation Engineers.

Copying of material in this book for internal or personal use, or for the internal or personal use of specific clients, beyond the fair use provisions granted by the U.S. Copyright Law is authorized by SPIE subject to payment of copying fees. The Transactional Reporting Service base fee for this volume is $\$ 18.00$ per article (or portion thereof), which should be paid directly to the Copyright Clearance Center (CCC), 222 Rosewood Drive, Danvers, MA 01923. Payment may also be made electronically through CCC Online at copyright.com. Other copying for republication, resale, advertising or promotion, or any form of systematic or multiple reproduction of any material in this book is prohibited except with permission in writing from the publisher. The CCC fee code is 0277-786X/12/\$18.00.

Printed in the United States of America.

Publication of record for individual papers is online in the SPIE Digital Library.

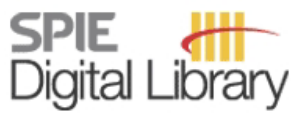

SPIEDigitallibrary.org

Paper Numbering: Proceedings of SPIE follow an e-First publication model, with papers published first online and then in print and on CD-ROM. Papers are published as they are submitted and meet publication criteria. A unique, consistent, permanent citation identifier (CID) number is assigned to each article at the time of the first publication. Utilization of CIDs allows articles to be fully citable as soon as they are published online, and connects the same identifier to all online, print, and electronic versions of the publication. SPIE uses a six-digit CID article numbering system in which:

- The first four digits correspond to the SPIE volume number.

- The last two digits indicate publication order within the volume using a Base 36 numbering

system employing both numerals and letters. These two-number sets start with 00, 01, 02, 03, 04, 05, 06, 07, 08, 09, 0A, 0B ... 0Z, followed by 10-1Z, 20-2Z, etc.

The CID Number appears on each page of the manuscript. The complete citation is used on the first page, and an abbreviated version on subsequent pages. Numbers in the index correspond to the last two digits of the six-digit CID Number. 


\section{Contents}

vii Symposium Committees

ix Conference Committee

xi Quantum dot lasers and relevant nanoheterostructures (Plenary Paper) [8552-1]

A. E. Zhukov, N. V. Kryzhanovskaya, A. V. Savelyev, A. M. Nadtochiy, E. M. Arakcheeva, F. I. Zubov, V. V. Korenev, Saint Petersburg Academic Univ. (Russian Federation); M. V. Maximov, Y. M. Shernyakov, M. M. Kulagina, I. A. Slovinskiy, loffe Physical-Technical Institute (Russian Federation); D. A. Livshits, Innolume GmbH (Germany); A. Kapsalis, C. Mesaritakis, D. Syvridis, Univ. of Athens (Greece); A. Mintairov, Univ. of Notre Dame (United States)

\section{HIGH POWER LASERS}

855102 Theoretical and experimental investigation of Rb-Ar excimer pumped alkali laser characteristics [8551-2]

D. Yue, W. Li, H. Wang, Z. Yang, X. Xu, National Univ. of Defense Technology (China)

855103 Gas dynamic effect in high energy fluid diode pumped alkali vapor laser [8551-3]

Y. XU, W. Li, H. Wang, Z. Yang, X. Xu, National Univ. of Defense Technology (China)

855104 Competition between spontaneous radiation and ionization in the process of resonance enhanced multi-photon ionization [8551-4]

G. Zhang, H. Li, H. Zheng, H. Ji, North China Electric Power Univ. (China)

\section{SLAB LASERS I}

855105 Variation of thermal lens curvature type between the convex and the concave lens for zigzag slab laser [8551-5]

X. Fu, Q. Liu, M. Gong, Tsinghua Univ. (China)

$855106 \quad$ Nonlinear imaging properties of two parallel gain-typed wirelike scatterers [8551-7] J. Huang, Y. Hu, Hunan Univ. of Science and Technology (China)

855107 In-situ measurement based on prior calibration with analogist samples for laser cladding [8551-8]

J. Liu, Y. Wu, L. Wang, Hunan Univ. (China)

855108 Temperature and align effects on efficiency of cholesteric liquid crystal based laser [8551-9]

F. Wang, Y. Liu, X. Liu, W. Sun, Harbin Engineering Univ. (China)

855109 Evaluation method of thermal recovery uniformity for high energy amplifier [8551-10]

Z. Ren, J. Zhu, Shanghai Institute of Optics and Fine Mechanics (China) 
8551 OA Ultra-fast ytterbium fiber laser operating at low repetition rate (Invited Paper) [8551-11] J.-B. Lecourt, S. Boivinet, Y. Hernandez, Multitel ASBL (Belgium)

8551 OB Single-mode linearly polarized high power fiber laser at $1120 \mathrm{~nm}$ [8551-12] J. Wang, Shanghai Institute of Optics and Fine Mechanics (China) and National Univ. of Defense Technology (China); J. Hu, L. Zhang, Shanghai Institute of Optics and Fine Mechanics (China); J. Chen, National Univ. of Defense Technology (China); Y. Feng, Shanghai Institute of Optics and Fine Mechanics (China)

8551 OE Femtosecond fiber lasers for biomedical solutions [8551-15] J. Liu, L. Yang, PolarOnyx, Inc. (United States)

SLAB LASERS II

8551 OG Design and modeling of 10-kW level single-side-pumped slab laser amplifier chain [8551-17]

X. Fu, M. Gong, Tsinghua Univ. (China)

\section{ULTRAFAST LASERS}

8551 OM Mode-locking characteristics of all-solid-state mode-locked laser with graphene saturable absorber [8551-26]

J. Wang, L. Wang, Beijing Univ. of Technology (China)

8551 OP Coherent beam combination of seven high power fiber amplifers with an all-optical feedback loop [8551-30]

H. Liu, Shanghai Institute of Optics and Fine Mechanics (China) and Graduate Univ. of the Chinese Academy of Sciences (China); B. He, J. Zhou, C. Liu, Shanghai Institute of Optics and Fine Mechanics (China); L. Hao, S. Dai, Shanghai Institute of Optics and Fine Mechanics (China) and Graduate Univ. of the Chinese Academy of Sciences (China); Y. Qi, X. Chen, Shanghai Institute of Optics and Fine Mechanics (China)

$85510 Q$ Phase and spectrum control requirements of high intensity laser beam combining [8551-31] Y. Gao, Z. Cao, X. Yang, W. Feng, W. Ma, Shanghai Institute of Laser Plasma (China); B. Zhu, Shanghai Institute of Optics and Fine Mechanics (China); J. Zhu, Y. Dai, Shanghai Institute of Laser Plasma (China)

\section{DIODE PUMPED LASERS}

8551 OR Fiber coupled high-power multi-mode diode pump lasers [8551-32]

T. Wang, L. Jiang, Q. He, H. Hu, Oclaro (Shenzhen) Co. Ltd. (China); N. Zayer, Oclaro Technology Ltd. (United Kingdom); R. Baettig, Oclaro, Inc. (Switzerland); S. Cutillas, D. Lenarduzzi, E. Wolak, Oclaro, Inc. (United States); B. Valk, Oclaro, Inc. (Switzerland) 
8551 OT A novel external cavity with double volume Bragg gratings for rubidium laser pumping [8551-35]

Z. Li, Institute of Electronics (China) and Graduate Univ. of the Chinese Academy of Sciences (China); R. Tan, Institute of Electronics (China); C. XU, L. Li, Institute of Electronics (China) and Graduate Univ. of the Chinese Academy of Sciences (China)

NOVEL LASERS

8551 OU High average power (11 W) eye-safe diamond Raman laser [8551-36]

A. McKay, O. Kitzler, H. Liu, D. Fell, R. P. Mildren, Macquarie Univ. (Australia)

POSTER SESSION

8551 OY Q-switched quasi-concentric laser resonator with line-shaped end-pumping profile: power-insensitive operating point and symmetrized TEMoo output [8551-6] X. Fu, Q. Liu, M. Gong, Tsinghua Univ. (China)

$85510 Z$ Modeling of distributed-side-pumped slab lasers: power scaling by adding slab units [8551-19]

X. Fu, Q. Liu, M. Gong, Tsinghua Univ. (China)

855110 Adaptive optics technology for Fourier telescopy [8551-22]

C. Lu, X. Gao, J. Tang, J. Wang, Beijing Institute of Tracking and Telecommunication Technology (China)

855112 Treatment of numerical overflow in simulating error performance of free-space optical communication [8551-41]

F. Li, Anhui Institute of Optics and Fine Mechanics (China) and Univ. of Science and Technology of China (China); Z. Hou, Y. Wu, Anhui Institute of Optics and Fine Mechanics (China)

855113 Parameters optimization of the beam clean-up system based on stochastic parallel gradient descent method [8551-42]

S. Wang, National Univ. of Defense Technology (China) and Taiyuan Satellite Launch Ctr. (China); J. Cui, Taiyuan Satellite Launch Ctr. (China); H. Ma, Y. Liang, Q. Yu, National Univ. of Defense Technology (China)

$855114 \quad$ Numerical analysis of thermal effects in micro-evaporator cooling module [8551-43] S. Fan, P. Zhang, Y. Liang, Y. Zhang, Chongaing Normal Univ. (China)

855115 Q-switched Yb-doped double cladding fiber laser with single wall carbon nanotube saturable absorber [8551-44]

Z. YU, Y. Song, C. Tian, J. Li, X. Zhang, Beijing Univ. of Technology (China); Y. Wang, The Hong Kong Polytechnic Univ. (China)

855117 Temperature distribution of laser crystal in LD end-pumped Nd:YAG/LBO blue laser [8551-49]

L. Zhang, Y. Zheng, S. Li, L. Jia, J. Kang, Shijiazhuang Univ. of Economics (China) 
855118 Oxygen partial pressure influence on the character of InGaZnO thin films grown by PLD [8551-46]

Y. Lu, L. Wang, Beijing Univ. of Technology (China)

855119 Passively Q-switched Nd:YCOB laser with a single-walled carbon nanotube saturable absorber [8551-47]

J. Li, Y. Song, Z. Yu, C. Tian, Y. Li, Beijing Univ. of Technology (China); Y. Wang, The Hong

Kong Polytechnic Univ. (Hong Kong, China)

8551 1 A Optical properties of single-walled carbon nanotubes and its applications in Q-switched lasers [8551-48]

C. Tian, Y. Song, J. Li, Z. Yu, Beijing Univ. of Technology (China); Y. Wang, Academia Sinica (Taiwan); Y. Li, Beijing Univ. of Technology (China)

8551 1C Numerical analysis of beam quality factor $\beta$ on coherent combination of multiple laser beams [8551-51]

Y. Tan, Institute of Optics and Electronics (China), The Key Lab. Of Adaptive Optics (China), and Graduate School of the Chinese Academy of Sciences (China); X. Li, Institute of Optics and Electronics (China) and The Key Lab. of Adaptive Optics (China)

8551 1E Narrow linewidth, wavelength-stable Er/Yb co-doped fiber MOPA source operating at $1547.8 \mathrm{~nm}[8551-53]$

H. Su, X. Li, Z. Dai, L. Xu, X. Li, Hebei Univ. (China)

8551 iF High power diode-pumped composite $\mathrm{YVO}_{4} / \mathrm{Nd}_{\mathrm{YVO}} / \mathrm{YVO}_{4}$ actively Q-switched and mode-locked laser with ring resonator [8551-55]

G. Huang, X. Xie, Z. Ou, C. Du, Shenzhen Univ. (China) and Shenzhen Key Lab. of Laser Engineering (China)

$8551 \mathrm{1H} \quad$ Microwave synthesis of Au nanoparticles as promising SERS substrates [8551-58]

L. Wang, S. Feng, N. Liu, J. Lei, H. Lin, Fujian Normal Univ. (China); L. Sun, First Hospital of Fuzhou (China); R. Chen, Fujian Normal Univ. (China)

$85511 \mathrm{~J}$ Characteristic research of the waveguide by nanosecond laser pulses on $\mathrm{LiNbO}_{3}$ [8551-60] Z. Zhou, C. Luo, Z. Fan, E. Quan, W. Zhu, L. Wang, Y. Yang, Southwest Univ. of Science and Technology (China)

8551 1K An equivalent method to analyze the electrical effect induced by laser plasma [8551-62] Y. Ji, C. Wang, B. Bian, Nanjing Univ. of Science and Technology (China)

Author Index 


\title{
Symposium Committees
}

\author{
General Chairs
}

Eustace L. Dereniak, College of Optical Sciences, The University of Arizona (United States)

Bingkun Zhou, Tsinghua University (China)

General Cochairs

Arthur Chiou, National Yang-Ming University (Taiwan, China)

Zhizhan Xu, Shanghai Institute of Optics and Fine Mechanics (China)

Jianlin Cao, China Ministry of Science and Technology (China)

Junhao Chu, Shanghai Institute of Technical Physics (China)

Technical Program Chairs

Songlin Zhuang, Shanghai University of Science and Technology (China)

Xingde Li, Johns Hopkins University (United States)

Technical Program Cochairs

Qiming Wang, Institute of Semiconductors (China)

Xu Liu, Zhejiang University (China)

Daoyin Yu, Tianjin University (China)

Qihuang Gong, Peking University (China)

Tianchu Li, National Institute of Metrology (China)

Wei Huang, Nanjing University of Posts and Telecommunications (China)

Local Organizing Committee Chair

Guangcan Guo, University of Science and Technology of China (China) 
Local Organizing Committee Cochairs

Guoqiang Ni, Beijing Institute of Technology (China)

Shusen Xie, Fujian Normal University (China)

Xiaomin Ren, Beijing University of Posts and Telecommunications (China)

Ying Gu, PLA General Hospital (China)

Huilin Jiang, Changchun University of Science and Technology (China)

General Secretary

Qihuang Gong, Peking University (China)

Local Organizing Committee

Yan Li, Chinese Optical Society/Peking University (China)

Zhiping Zhou, Peking University (China)

Changhe Zhou, Shanghai Institute of Optics and Fine Mechanics (China)

Qingming Luo, Huazhong University of Science and Technology (China)

Chongxiu Yu, Beijing University of Posts and Telecommunications (China)

Hongda Chen, Institute of Semiconductors (China)

Yongtian Wang, Beijing Institute of Technology (China)

Yiping Cui, Southeast University (China)

Xuping Zhang, Nanjing University (China)

Feijun Song, Daheng Corporation (China)

Cunlin Zhang, Capital Normal University (China)

Yanting Lu, Nanjing University (China)

Yuejin Zhao, Beijing Institute of Technology (China)

Chunqing Gao, Beijing Institute of Technology (China)

Tiegen Liu, Tianjin University (China)

Xiaocong Yuan, Nankai University (China)

Weimin Chen, Chongqing University (China)

Zhongwei Fan, Academy of Optoelectronics (China)

Hanyi Zhang, Tsinghua University (China)

Lan Wu, Zhejiang University (China)

Yongsheng Zhang, University of Science and Technology of China (China)

Hong Yang, Peking University (China)

Xiaoying Li, Tianjin University (China)

Lin Zhai, Chinese Optical Society (China) 


\section{Conference Committee}

Conference Chairs

Upendra N. Singh, NASA Langley Research Center (United States)

Dianyuan Fan, Shanghai Institute of Optics and Fine Mechanics

(China)

Jianquan Yao, Tianjin University (China)

Robert F. Walter, Schafer Corporation (United States)

Conference Program Committee

Willy L. Bohn, BohnLaser Consult (Germany)

Robert L. Byer, Stanford University (United States)

ShuShen Deng, China Daheng Group, Inc. (China)

Tomoo Fujioka, Tokai University (Japan)

Mali Gong, Tsinghua University (China)

Do-Kyeong Ko, Gwangju Institute of Science and Technology

(Korea, Republic of)

Ruxin Li, Shanghai Institute of Optics and Fine Mechanics (China)

Zejin Liu, National University of Defense Technology (China)

DeYuan Y. Shen, Fudan University (China)

Yi Su, Institute of Applied Electronics (China)

Shuangchun Wen, Hunan University (China)

Zuyan Xu, Institute of Physics (China)

Tai Hyun Yoon, Korea University (Korea, Republic of)

Jirong Yu, NASA Langley Research Center (United States)

Xiaomin Zhang, China Academy of Engineering Physics (China)

Shouhuan Zhou, North China Research Institute of Electro-Optics (China)

\section{Session Chairs}

1 High Power Lasers

Upendra N. Singh, NASA Langley Research Center (United States)

2 Slab Lasers I

Jirong Yu, NASA Langley Research Center (United States)

3 Fiber Lasers

Robert F. Walter, Schafer Corporation (United States)

4 Slab Lasers II

Jinxue Wang, Ratheon Company (United States) 
5 Laser Applications

Willy L. Bohn, BohnLaser Consult (Germany)

6 Ultrafast Lasers

Han Zhang, Hunan University (China)

7 Diode Pumped Lasers

Willy L. Bohn, BohnLaser Consult (Germany)

8 Novel Lasers

Han Zhang, Hunan University (China) 